\title{
Type of Renal Replacement Therapy (Hemodialysis versus Peritoneal Dialysis) Does Not Affect Cytokine Gene Expression or Clinical Parameters of Renal Transplant Candidates
}

\author{
Dorota Kamińska, ${ }^{1}$ Katarzyna Kościelska-Kasprzak, ${ }^{1}$ \\ Pawel Chudoba, ${ }^{2}$ Oktawia Mazanowska, ${ }^{1}$ Mirosław Banasik, ${ }^{1}$ \\ Marcelina Żabinska, ${ }^{1}$ Maria Boratyńska, ${ }^{1}$ Agnieszka Lepiesza, ${ }^{2}$ Krzysztof Korta, ${ }^{2}$ \\ Agnieszka Gomółkiewicz, ${ }^{3}$ Piotr Dzięgiel, ${ }^{3}$ and Marian Klinger ${ }^{1}$ \\ ${ }^{1}$ Department of Nephrology and Transplantation Medicine, Wroclaw Medical University, Borowska 213, 50-556 Wrocław, Poland
${ }^{2}$ Department of Vascular, General and Transplant Surgery, Wroclaw Medical University, Borowska 213, 50-556 Wrocław, Poland
${ }^{3}$ Department of Histology and Embryology, Wroclaw Medical University, Chałubinskiego 6a, 50-368 Wrocław, Poland
}

Correspondence should be addressed to Dorota Kamińska; dorotakaminska@interia.pl

Received 9 January 2015; Revised 24 May 2015; Accepted 23 June 2015

Academic Editor: Detlef H. Krieter

Copyright (C) 2015 Dorota Kamińska et al. This is an open access article distributed under the Creative Commons Attribution License, which permits unrestricted use, distribution, and reproduction in any medium, provided the original work is properly cited.

Patients with renal failure suffer from immune disturbances, caused by uremic toxins and influenced by dialysis treatment. The aim of the present study was to reveal whether type of dialysis modality (hemodialysis, HD, versus peritoneal dialysis, PD) differentially affects the immunocompetence, particularly the expression of genes involved in the immune response. Material. 87 renal transplant candidates (66 HD, $21 \mathrm{PD}$ ) were included in the study. Methods. The peripheral blood RNA samples were obtained with the PAXgene Blood system just before transplantation. The gene expression of CASP3, FAS, TP53, FOXP3, IFNG, IL2, IL6, IL8, IL10, IL17, IL18, LCN2, TGFB1, and TNF was assessed with real-time PCR on custom-designed low density arrays (TaqMan). Gene expression data were analyzed in relation to pretransplant clinical parameters. Results. The mean expression of examined genes showed no significant differences between PD and HD with the exception of FAS, expression of which was 30\% higher in PD patients compared to the HD group. There was nonsignificantly higher expression of proinflammatory cytokines in the PD group. The clinical inflammatory parameters (CRP, albumin, cholesterol, and hemoglobin levels) did not differ between the groups. Conclusion. Type of renal replacement therapy exerts no differential effect on cytokine gene expression or inflammatory clinical parameters.

\section{Introduction}

End stage renal disease (ESRD) is known to be a state of immune incompetence, which results in various immune abnormalities. Systemic and local microinflammation accompanied by immune deficiency is observed in patients with uremia. Inadequate responsiveness to vaccination, for example, hepatitis B, was described in patients with ESRD [1]. These patients are also more susceptible to viral as well as bacterial infections, which are the second (after cardiovascular) leading cause of mortality during renal replacement therapy [2]. The influence of malnutrition and inflammatory cytokines on cardiovascular risk, infection, and mortality rate has been extensively examined. Uremia and secondary hyperparathyroidism have been known since the 1990s to impact B and T lymphocyte function $[3,4]$ and antibody production [5].

Recently, uremia was reported to influence cytokine synthesis [6]. Partially this phenomenon can be explained by the neutrophil deficiency, as well as changes in neutrophil function in ESRD [7]. The chronic inflammation can be detected by elevated blood levels of C-reactive protein (CRP) and some cytokines, for example, IL-6, IL-18, IL-10, and TNFalpha $[8,9]$. Also abnormal function of regulatory $\mathrm{T}$ cells in 
TABLE 1: Subject characteristics.

\begin{tabular}{|c|c|c|c|}
\hline & HD patients $(n=66)$ & PD patients $(n=21)$ & $p$ \\
\hline Age (years, mean $\pm S D$, median $[\mathrm{IQR}]$ ) & $\begin{array}{c}48 \pm 12 \\
53.5[19-72]\end{array}$ & $\begin{array}{c}42 \pm 14 \\
40[16-68]\end{array}$ & $0.084^{* *}$ \\
\hline Gender (female/male) & $39(59 \%) / 27(41 \%)$ & $14(67 \%) / 7(33 \%)$ & 0.72 \\
\hline Time of dialysis (months, mean $\pm \mathrm{SD}$, median $[\mathrm{IQR}]$ ) & $\begin{array}{c}33 \pm 42 \\
24.5[13-36]\end{array}$ & $\begin{array}{c}15 \pm 10 \\
15[6-22]\end{array}$ & $0.017^{* *}$ \\
\hline BMI $\left(\mathrm{kg} / \mathrm{m}^{2}\right)$ & $24.6 \pm 3.6$ & $24.8 \pm 3.7$ & $0.80^{*}$ \\
\hline \multicolumn{4}{|l|}{ Primary disease } \\
\hline Diabetic nephropathy & $4(6 \%)$ & $5(24 \%)$ & \\
\hline Chronic glomerulonephritis & $22(33 \%)$ & $12(57 \%)$ & \\
\hline Hypertensive nephropathy & $7(11 \%)$ & $1(5 \%)$ & \\
\hline Polycystic renal disease & $9(14 \%)$ & $1(5 \%)$ & \\
\hline Chronic interstitial nephritis & $16(24 \%)$ & 0 & \\
\hline Unknown & $8(12 \%)$ & $2(9 \%)$ & \\
\hline
\end{tabular}

PD: continuous ambulatory peritoneal dialysis; ${ }^{*}$ from $t$-tests; ${ }^{* *}$ from Mann-Whitney $U$-test.

uremia [10] and an imbalance of immature and memory B cells have been reported [11].

The above-described abnormalities are further enhanced by renal replacement therapy. Activation of the Th2 pathway with a potential tolerogenic effect was observed during hemodialysis [12]. Moreover, the peritoneal dialysis (especially with lactate-buffered peritoneal fluids) exerted deleterious effects on the Th1 cell subsets and promoted the Th2 type of immune response [13]. In contrast, some authors reported no influence of renal replacement therapy on cytokine and serum CRP levels [14].

While immune defects are well described in the literature, still it is not clear whether the type of dialysis modality (hemodialysis versus peritoneal dialysis) differentially affects the immunocompetence, particularly the expression of genes involved in the immune response and inflammation with the change in inflammatory gene profiles in patients on the active transplant waiting list. The aim of this study was to investigate pretransplant blood cytokine and apoptosis related gene expression to reveal possible difference in patients on hemodialysis (HD) and peritoneal dialysis (PD) in relation to clinical indices of malnutrition as well as inflammatory processes.

We focused on the immune factors known to be related to tissue injury and inflammation (IL-6, IL-8, IL-17, IL-18, NGAL, and TNF-alpha), apoptosis (Fas, caspase-3, and p53) and Th1 lymphocyte activation (IFN-gamma, IL-2), as well as Th2 (IL-10, TGF-betal), and regulatory $\mathrm{T}$ cell function (FoxP3).

\section{Material}

The study was carried out on 87 renal transplant candidates (aged 16-72 years, mean 47 years; 34 females, 53 males) who had been admitted to hospital for transplantation surgery. Among them 66 patients were treated with hemodialysis and
21 patients with peritoneal dialysis. Patients' characteristics are presented in Table 1.

All HD patients were treated by low-flux hemodialysis on polysulfone membrane dialyzers with bicarbonatecontaining solutions for $4 \mathrm{~h}$ three times weekly.

All patients from PD group were on continuous ambulatory peritoneal dialysis. The standard solutions of 21 volume with various concentrations of glucose (mostly 3 times with $1.36 / 1.5 \%$, and one time with $2.3 \%$ ) were used. No icodextrinor amino acid-containing solutions were used.

Weekly Kt/V > 1.7 was reported in all PD patients. In $\mathrm{HD}$ group in all subjects' single pool Kt/V per session was $>1.2$. Patients remained on renal replacement therapy from 1 to 97 months (mean $25 \pm 18$ months).

Blood samples for routine laboratory tests as well as gene expression were taken during immediate pretransplant examination before introducing immunosuppressive therapy. The samples were obtained at least 6 hours after the last $\mathrm{HD}$ session or at least 4 hours after the last peritoneal fluid removal.

Clinical data were obtained from medical records from patients' dialysis centers.

The project was performed after approval from the Commission of Bioethics at Wroclaw Medical University, and all aspects of the study were in accordance with the World Medical Association Declaration of Helsinki. Each patient read an information sheet and provided fully informed consent.

\section{Methods}

The peripheral blood samples were obtained with PAXgene Blood RNA tubes. RNA was isolated with a PAXgene Blood RNA kit (PreAnalytics) and reversely transcribed with a High Capacity RNA to cDNA kit (Applied Biosystems). The peripheral blood gene expression of caspase-3 (CASP3, Hs00263337_m1), 
TABLE 2: Clinical pretransplant laboratory parameters (mean $\pm \mathrm{SD}$, for not normally distributed values also median [IQR]).

\begin{tabular}{|c|c|c|c|}
\hline & HD patients $(n=66)$ & PD patients $(n=21)$ & \\
\hline $\mathrm{Hgb}(\mathrm{g} / \mathrm{dL})$ & $11.1 \pm 1.7$ & $10.8 \pm 1.4$ & $0.54^{*}$ \\
\hline WBC count $\left(\times 10^{3} / \mathrm{mcL}\right)$ & $\begin{array}{c}7.4 \pm 2.3 \\
7[5.1-8.4]\end{array}$ & $\begin{array}{c}7.5 \pm 3.3 \\
7.1[5.8-8.8]\end{array}$ & $0.84^{* *}$ \\
\hline PLT count $\left(\times 10^{3} / \mathrm{mcL}\right)$ & $\begin{array}{c}198 \pm 64 \\
225[181-268]\end{array}$ & $\begin{array}{c}230 \pm 65 \\
188[155-237]\end{array}$ & $0.06^{* *}$ \\
\hline $\mathrm{CRP}(\mathrm{mg} / \mathrm{L})$ & $\begin{array}{c}6.9 \pm 7.0 \\
1.2[0.7-3.6]\end{array}$ & $\begin{array}{c}3.2 \pm 4.6 \\
3.5[1.2-6.6]\end{array}$ & $0.11^{* *}$ \\
\hline Cholesterol (mg/dL) & $181 \pm 57$ & $206 \pm 40$ & $0.11^{*}$ \\
\hline Albumin (g/dL) & $4.2 \pm 0.8$ & $3.9 \pm 0.8$ & $0.31^{*}$ \\
\hline Creatinine $(\mathrm{mg} / \mathrm{dL})$ & $\begin{array}{c}7.0 \pm 2.0 \\
5.6[5.2-9.7]\end{array}$ & $\begin{array}{c}7.4 \pm 2.8 \\
6.8[5.1-8.6]\end{array}$ & $0.90^{* *}$ \\
\hline Uric acid (mg/dL) & $\begin{array}{c}5.4 \pm 2.8 \\
6.5[5.8-8.0]\end{array}$ & $\begin{array}{c}6.9 \pm 1.4 \\
4.9[4.1-5.7]\end{array}$ & $0.015^{* *}$ \\
\hline iPTH (pg/mL) & $\begin{array}{c}320 \pm 257 \\
428[221-797]\end{array}$ & $\begin{array}{c}500 \pm 371 \\
256[185-398]\end{array}$ & $0.29^{* *}$ \\
\hline $\operatorname{Iron}(\mathrm{mg} / \mathrm{dL})$ & $67.7 \pm 27.2$ & $69.1 \pm 30.8$ & $0.87^{*}$ \\
\hline Transferrin saturation (\%) & $29.5 \pm 11.1$ & $26.2 \pm 11.1$ & $0.36^{*}$ \\
\hline
\end{tabular}

WBC: white blood cell; PLT: platelet; ${ }^{*}$ from $t$-tests; ${ }^{* *}$ from Mann-Whitney $U$-test.

FAS (FAS, Hs00236330_m1), p53 (TP53, Hs00153349_m1), FOXP3 (FOXP3, Hs00203958_m1), IFN-gamma (IFNG, Hs0 0174143_ml), interleukin-2 (IL2, Hs00174114_m1), interleukin6 (IL6, Hs00174131_ml), interleukin-8 (IL8, Hs00174103_m1), interleukin-10 (IL10, Hs00174086_m1), interleukin-17 (IL17A, Hs99999082_ml), interleukin-18 (IL18, Hs00155517_m1), NGAL (LCN2, Hs00194353_m1), TGF-beta (TGFB1, Hs99999918_m1), and TNF-alpha (TNF, Hs00174128_ml) was assessed with real-time PCR on custom-designed low density arrays (TaqMan) with TaqMan PCR Master Mix. All procedures were performed according to the manufacturer protocols. GAPDH (Hs99999905_ml) was chosen as a reference gene and proved to be invariant between the studied groups.

The expression data are presented as $\Delta \Delta \mathrm{Ct}=\Delta \mathrm{Ct}_{\mathrm{HD}}-$ $\Delta \mathrm{Ct}_{\text {sample, }}$, where $\Delta \mathrm{Ct}_{\mathrm{HD}}$ is the mean value of $\Delta \mathrm{Ct}_{\text {sample }}$ for $\mathrm{HD}$ group, $\Delta \mathrm{Ct}_{\text {sample }}=\mathrm{Ct}_{\text {gene }}-\mathrm{Ct}_{\mathrm{GAPDH}}$, and $\mathrm{Ct}$ is the cycle threshold value and defines the calculated cycle number, in which the fluorescence measured during the PCR reaction increases over the preset threshold value. The abovementioned equation provides expression data related both to the GAPDH reference gene and to the mean expression level for $\mathrm{HD}$, which is considered a reference group here. The relative change in the observed expression of $\mathrm{PD}$ versus $\mathrm{HD}$ is calculated as $2^{-\Delta \Delta \mathrm{Ct}}$ for mean $\Delta \Delta \mathrm{Ct}$ for $\mathrm{PD}$.

3.1. Statistical Analysis. Statistical analysis was performed using the Statistica v.10 statistical package (StatSoft, Poland). The chi-square test was used to evaluate the difference in proportions between two groups. The assumption of normality was tested for each continuous variable. The difference between the two groups was evaluated with a $t$-test or, in the case of lack of normality, it was analyzed with the MannWhitney $U$-test. The correlations were tested with Pearson correlation or Spearman correlation, respectively. $p<0.05$ was considered significant.

\section{Results}

4.1. Clinical Parameters. The groups of patients did not differ significantly according to age, gender, or BMI distribution. The time of renal replacement therapy was significantly shorter in the PD group compared to the HD group (median [IQR]: 15 [6-22] versus 24.5 [13-36] months, resp.).

The clinical pretransplant blood parameters are presented in Table 2. The clinical inflammatory parameters (CRP, albumin, cholesterol, and hemoglobin levels) and serum creatinine as well as iron level with transferrin saturation and iPTH did not differ between the groups. Only pretransplant serum uric acid concentration was significantly higher in the PD group (median [IQR]: 4.9 [4.1-5.7] versus 6.5 [5.8-8.0] mg/dL). Patient's age and CRP levels were lower in the PD group, but the differences did not reach statistical significance.

4.2. Gene Expression. The mean expression levels of the genes are presented in Table 3. IL17 gene expression was undetectable in all patients.

The mean serum expression of the genes showed no significant differences between PD and HD with the exception of FAS, expression of which was 1.29 times higher (95\% CI 1.031.61) in PD patients compared to the HD group (Figure 1).

Although higher gene expression of proinflammatory cytokines (IFNG, IL6, and IL18) in the PD group was noted, the differences were not statistically significant. Also, the lower IL10 and higher TGFB1 gene expression observed in the PD group were not statistically significant.

We found significantly lower (0.68x, 95\% CI 0.50-0.93) relative expression of IL10 to FAS in the PD group compared to the HD group ( $t$-test, $p=0.013)$. We also observed lower $(0.74 \mathrm{x}, 95 \%$ CI $0.55-1.01)$ relative expression of IL10 to IL18 of borderline significance $(t$-test, $p=0.054)$. Lower $(0.60 \mathrm{x}$, 
TABLE 3: Mean expression level of the studied genes in PD group presented as $\Delta \Delta \mathrm{Ct}$ in relation to mean value for $\mathrm{HD}$. As a rule, the HD group mean value is always equal to zero.

\begin{tabular}{lc}
\hline Gene & PD $(n=21)$, mean \pm SD \\
\hline Apoptosis & $0.17 \pm 0.97$ \\
CASP3 & $\mathbf{0 . 3 6} \pm \mathbf{0 . 5 7}$ \\
FAS & $0.08 \pm 0.42$ \\
TP53 & \\
Inflammation & $0.17 \pm 1.72$ \\
IL6 & $0.15 \pm 1.01$ \\
IL8 & $0.19 \pm 0.57$ \\
IL18 & $0.14 \pm 0.45$ \\
TNF & $0.05 \pm 1.44$ \\
LCN2 & \\
Th1 & $0.59 \pm 1.54$ \\
IFNG & $-0.19 \pm 1.70$ \\
IL2 & \\
Th2 & $-0.26 \pm 0.64$ \\
IL10 & $0.15 \pm 0.32$ \\
TGFB1 & \\
Treg & $0.03 \pm 0.70$ \\
FOXP3
\end{tabular}

${ }^{*} t$-test $p=0.023$.

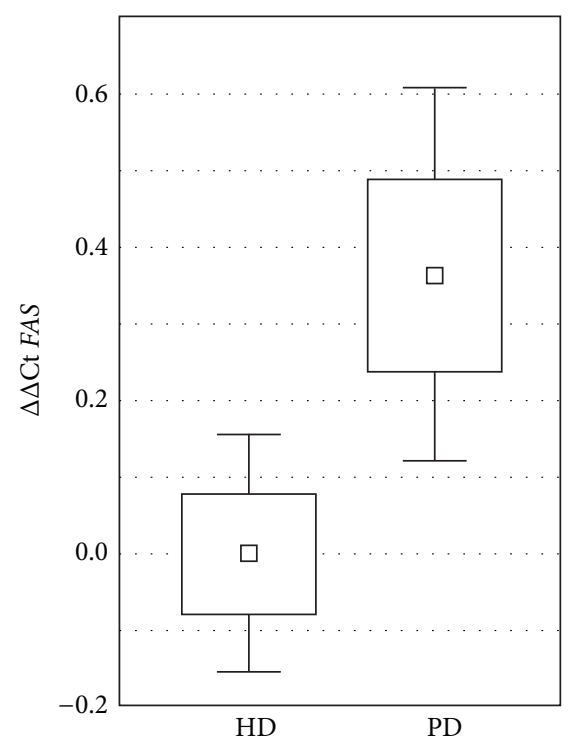

FIGURE 1: $\triangle \triangle \mathrm{Ct}$ describing relative gene expression of $F A S$ versus $G A P D H$ in peritoneal dialysis (PD) and hemodialysis (HD) group, related to the mean for HD samples. Graph presented as square: mean, box: mean \pm SE, and whiskers: $95 \% \mathrm{CI}$.

95\% CI 0.35-1.04) relative expression of IL10 to IFNG in the PD group compared to the HD group did not reach statistical significance ( $t$-test, $p=0.074)$.

The expression of some genes was related to clinical parameters of the patients. The correlations are presented in Table 4. The time of renal replacement therapy did not influence expression of any of the examined genes.
TABLE 4: Statistically significant correlations between gene expression $(\Delta \Delta \mathrm{Ct})$ and clinical parameters.

\begin{tabular}{lccc}
\hline Clinical parameter & Gene & Correlation coefficient & $p$ \\
\hline BMI & LCN2 & $0.44^{* *}$ & $<0.001$ \\
\hline Age at KTx & TP53 & $-0.32^{*}$ & 0.028 \\
\hline & FOXP3 & $-0.41^{* *}$ & 0.001 \\
& IL2 & $-0.33^{*}$ & 0.025 \\
WBC & IL6 & $-0.34^{*}$ & 0.020 \\
& LCN2 & $0.44^{*}$ & 0.002 \\
& TNF & $-0.36^{* *}$ & 0.005 \\
& TP53 & $-0.26^{* *}$ & 0.043 \\
\hline Serum albumin level & IL10 & $0.41^{*}$ & 0.004 \\
\hline
\end{tabular}

KTx: kidney transplantation; ${ }^{*}$ Pearson correlation; ${ }^{* *}$ Spearman rank correlation.

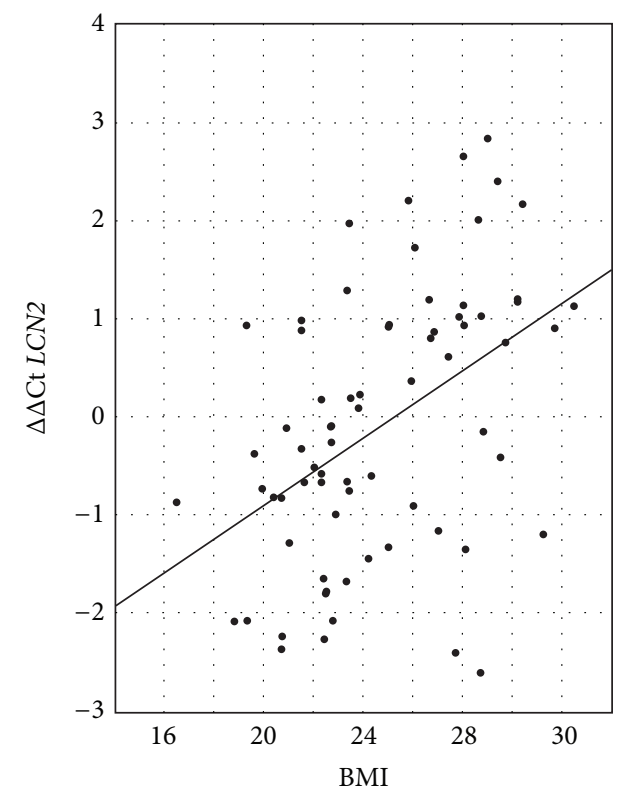

Figure 2: $\Delta \Delta \mathrm{Ct}$ describing relative gene expression of LCN2 (NGAL) versus BMI.

FOXP3 expression was negatively correlated with WBC in both groups ( $\mathrm{rs}=-0.41, p=0.01$, and $\mathrm{rs}=-0.34$ ), accompanied by IL2 and IL6 ( $\mathrm{rs}=-0.33, p=0.01$, and rs $=-0.34, p=0.009$, resp.). IL10 gene expression correlated significantly with albumin level ( $r s=0.41, p<0.004)$. LCN2 (NGAL) gene expression was positively correlated with WBC ( $\mathrm{rs}=0.44, p<0.002$ ). Also BMI was positively correlated with LCN2 gene expression ( $r s=0.44, p<0.001$ ) (Figure 2).

\section{Discussion}

End stage renal disease (ESRD) is associated with both inflammation and immune deficiency $[11,15,16]$. In our study we focused on the wide range of immune factors known to be related to inflammation, apoptosis, and lymphocyte Th1 and 
Th2 activation, as well as regulatory $\mathrm{T}$ cell function. It should be emphasized that the study encompassed the relatively healthy HD and PD patients just before transplantation. The general well-being of the patients allowed them to be qualified for renal transplantation and did not differ in terms of clinical indicators with the exception of the shorter dialysis treatment period in the PD group. In this selected group the main findings of our study were as follows: clinical symptoms of chronic inflammation in general did not differentiate the PD group from the HD group. Also the pro- and antiinflammatory gene expression was similar in both examined groups. A uniform type of Th1 and Th2 activation pattern was seen in both groups.

Only an intensified apoptosis rate with increased FAS gene expression was seen in $\mathrm{PD}$ patients compared to $\mathrm{HD}$ patients. Lowered relative expression of IL10 to proinflammatory cytokines (IL18, IL10, IL6, and IFNG) in the PD group compared to the HD group was also observed. The time of renal replacement therapy was the only clinical parameter that differentiated the HD group from the $\mathrm{PD}$ group. Nevertheless, the time of renal replacement therapy did not influence the expression of any of the examined genes. Therefore the observed upregulation of the FAS gene seems to be attributable solely to the type of dialysis.

Neutrophil deficiency and dysfunction due to not only uremic toxins but also malnutrition-inflammationatherosclerosis (MIA) syndrome and dialysis was reported [7]. Chronic inflammation with acceleration of atheromatosis is responsible for the high rate of morbidity and mortality in dialysis patients [2]. T-helper lymphocytes were polarized towards the Th2 phenotype with higher synthesis of IL- 4 and IL-10 in uremic patients and lower release of IFN-gamma [12]. Those reports suggest that uremia is associated with a predominance of Th 2 cells and a switch of cytokine synthesis towards depressed cell-mediated immunity [17]. In our study we observed the universal pattern of immune activation in patients on the active waiting list with no switch to either a Th1 or Th2 response.

Overactivated but functionally compromised Tregs were described in ESRD. The basal IL2 and FOXP3 mRNA levels were high but did not rise upon stimulation [10]. An imbalance of Treg/Th17 function when compared to the healthy controls was described in the ESRD group [18, 19]. In our study the IL17 gene expression was undetectable in all patients, so it was excluded from further analysis.

The laboratory indices of microinflammation include elevated blood levels of CRP and some cytokines, mainly IL6, IL-18, IL-10, and TNF-alpha, which correlated with acceleration of atherosclerosis $[8,9,20,21]$. Hypoalbuminemia was a risk factor for septicemia in dialysis patients [22]. Malnutrition may be caused by chronic inflammation via increased levels of proinflammatory cytokines [23]. No overt malnutrition was observed in our study patients. The study cohort consisted of patients on active waiting list, thus being a selected group of patients on RRT, healthier than average dialysis population. Also the detected albumin levels were within normal ranges for the majority of the patients. We observed that the albumin level correlated significantly with IL10 gene expression in all patients and in the HD group. This is an expected finding because hypoalbuminemia was described as a potent factor augmenting chronic inflammation [2426]. Anti-inflammatory mechanisms of IL-10 were reported to limit the production of a broad range of proinflammatory factors [27]. In our study we also observed that relative antiinflammatory IL10 gene expression to proinflammatory genes IL6, IFNG, and IL18 was lower in the PD group compared to the HD group. This fact may indicate the intensified inflammatory process in the $\mathrm{PD}$ group.

Chronic activation of the immune system may be further intensified by renal replacement therapy. Several studies were performed to elucidate whether the type of the dialysis technique may influence the induction of a chronic inflammatory state.

The use of different peritoneal fluids was associated with disturbed Th1/Th2 balance. Use of lactate-buffered peritoneal fluid has deleterious effects on the Thl cell when compared to both icodextrin solution and lactate/bicarbonate-buffered solution [13]. On the contrary no influence of biocompatibility of PD solutions on any parameter of MIA syndrome was reported [28]. Hwang et al. reported that IL6 gene polymorphism influenced the peritoneal solute transport rate in $\mathrm{PD}$ patients [29].

Opposing reports of no influence of renal replacement therapy on cytokine and serum CRP levels have been published [14]. In our study the CRP level was negatively correlated with TNF gene expression only in the PD group. The major cellular origin of TNF-alpha is activated macrophages. The previous reports of the association between CRP levels and TNF-alpha expression were inconsistent, indicating that the presence of TNF-alpha in blood depends on a complex relationship in the inflammatory response and may not reflect biologic activity at the tissue level [21]. In our study, almost all the patients from the HD group were examined more than 6 hours after hemodialysis, so the effect of the single session of hemodialysis on gene expression was not taken into account.

Increased apoptosis of leukocytes associated with increased serum Fas and p53 protein levels as well as decreased antiapoptotic bcl-2 gene expression from neutrophils has been described in ESRD patients [30, 31]. In our study we found that in PD patients the expression of proapoptotic FAS was significantly higher than in HD patients. Moreover, the expression of proapoptotic TP53 correlated negatively with WBC. The clinical meaning of this observation remains unclear, beyond a speculation on more balanced immune and inflammatory cell state in the PD transplant candidates. Also this observation supports the hypothesis that increased apoptosis of neutrophils influences total WBC in uremic patients.

Also we found that NGAL gene expression (LCN2) was positively correlated with WBC in all patients and the HD group. NGAL is a protein released mainly by neutrophils, but also renal tubular cells and some extrarenal cells, especially adipocytes [32,33], and strongly depends on their absolute number, so the positive correlation with WBC is not surprising and confirms other reports [34]. Moreover, we found a strong correlation of NGAL gene expression with BMI, which is in agreement with other authors' reports [35] and supports the observation that NGAL is closely associated with obesity. 


\section{Limitations of the Study}

Although according to our knowledge this is the first published report which compares cytokine and apoptosis-related gene expression directly between HD and PD patients in the pretransplant period, some potential limitations should be mentioned.

We analyzed data of more patients treated with HD than PD. The disparity between the number of patients treated with those two dialysis modalities reflects the global situation in renal replacement therapy. Less than 5\% of patients with end stage renal disease are treated with PD in Poland which is similar to the world's situation when less than $11 \%$ of the patients are treated with PD.

This study was based on single time-point assessment of inflammatory cytokine expression and clinical coefficients. We had no possibility of assessing time-dependent changes in cytokine gene expressions. The concept was chosen on the basis that patients eligible for transplantation do not currently suffer from any acute infection. Usually they present a very good clinical status with high dialysis efficiency. All the patients at the time of transplantation were clinically stable, with no signs of inflammation, with no records of cancer, inflammatory diseases, or immunosuppressive therapy. Our results were obtained for a relatively homogeneous group of potential recipients on an active waiting list, who are not representative of all patients on renal replacement therapy.

\section{Conclusion}

Type of the renal replacement therapy exerts no differential effect on cytokine gene expression or inflammatory clinical parameters with the exception of an increased apoptosis rate with increased FAS gene expression in $\mathrm{PD}$ patients compared to HD patients. Also, related anti-inflammatory IL10 gene expression towards proinflammatory cytokines was lowered in the PD group. Possibly uremia is the most potent factor which triggers immune activation, and further changes induced by the different types of renal replacement therapy are too subtle to be apparent. The intensity of the inflammatory response, measured by cytokine gene expression, may further influence the posttransplant alloimmune response and graft survival.

$\begin{array}{ll}\text { Abbreviations } \\ \text { BMI: } & \text { Body mass index } \\ \text { CASP3: } & \text { Caspase-3 gene } \\ \text { CRP: } & \text { C-reactive protein } \\ \text { eGFR: } & \text { Estimated glomerular filtration rate } \\ \text { FAS: } & \text { First apoptotic signal gene } \\ \text { FoxP3: } & \text { Forkhead box protein P3 } \\ \text { FOXP3: } & \text { Forkhead box protein P3 gene } \\ \text { GAPDH: } & \text { Glyceraldehyde 3-phosphate } \\ & \text { dehydrogenase gene } \\ \text { HD: } & \text { Hemodialysis } \\ \text { Hgb: } & \text { Haemoglobin } \\ \text { IFN-gamma: } & \text { Interferon gamma }\end{array}$

$\begin{array}{ll}\text { IFNG: } & \text { Interferon gamma gene } \\ \text { IL-2: } & \text { Interleukin-2 } \\ \text { IL2: } & \text { Interleukin-2 gene } \\ \text { IL-6: } & \text { Interleukin-6 } \\ \text { IL6: } & \text { Interleukin-6 gene } \\ \text { IL-8: } & \text { Interleukin-8 } \\ \text { IL8: } & \text { Interleukin-8 gene } \\ \text { IL-10: } & \text { Interleukin-10 } \\ \text { IL10: } & \text { Interleukin-10 gene } \\ \text { IL-17: } & \text { Interleukin-17 } \\ \text { IL17: } & \text { Interleukin-17 gene } \\ \text { IL-18: } & \text { Interleukin-18 } \\ \text { IL18: } & \text { Interleukin-18 gene } \\ \text { IQR: } & \text { Interquartile range } \\ \text { LCN2: } & \text { Neutrophil gelatinase-associated lipocalin } \\ & \text { gene } \\ \text { NGAL: } & \text { Neutrophil gelatinase-associated lipocalin } \\ \text { p53: } & \text { Tumor protein p53 } \\ \text { PCR: } & \text { Polymerase chain reaction } \\ \text { PD: } & \text { Peritoneal dialysis } \\ \text { PLT: } & \text { Platelet count } \\ \text { RRT: } & \text { Renal replacement therapy } \\ \text { TGF-beta: } & \text { Transforming growth factor beta } \\ \text { TGFB1: } & \text { Transforming growth factor beta gene } \\ \text { TNF-alpha: } & \text { Tumor necrosis factor alpha } \\ \text { TNF: } & \text { Tumor necrosis factor alpha gene } \\ \text { TP53: } & \text { Tumor protein p53 gene } \\ \text { WBC: } & \text { White blood cell. } \\ & \end{array}$

\section{Conflict of Interests}

The authors declare that there is no conflict of interests regarding the publication of this paper.

\section{Acknowledgment}

This study was supported by a research grant from the Polish Society of Nephrology funded by Baxter.

\section{References}

[1] M. Dinits-Pensy, G. N. Forrest, A. S. Cross, and M. K. Hise, “The use of vaccines in adult patients with renal disease," American Journal of Kidney Diseases, vol. 46, no. 6, pp. 997-1011, 2005.

[2] S. S. Lewis and D. J. Sexton, "Metastatic complications of bloodstream infections in hemodialysis patients," Seminars in Dialysis, vol. 26, no. 1, pp. 47-53, 2013.

[3] J. M. Alexiewicz, M. Klinger, T. O. Pitts, Z. Gaciong, M. LinkerIsraeli, and S. G. Massry, "Parathyroid hormone inhibits B cell proliferation: implications in chronic renal failure," Journal of the American Society of Nephrology, vol. 1, no. 3, pp. 236-244, 1990.

[4] J. M. Alexiewicz, Z. Gaciong, M. Klinger, M. Linker-Israeli, T. O. Pitts, and S. G. Massry, "Evidence of impaired T cell function in hemodialysis patients: potential role for secondary hyperparathyroidism," The American Journal of Nephrology, vol. 10, no. 6, pp. 495-501, 1990.

[5] R. Shurtz-Swirski, T. Shkolnik, and S. M. Shasha, "Parathyroid hormone and the cellular immune system," Nephron, vol. 70, no. 1, pp. 21-24, 1995. 
[6] R. A. Zager, A. C. M. Johnson, and S. Lund, "Uremia impacts renal inflammatory cytokine gene expression in the setting of experimental acute kidney injury," The American Journal of Physiology-Renal Physiology, vol. 297, no. 4, pp. F961-F970, 2009.

[7] M. Chonchol, "Neutrophil dysfunction and infection risk in end-stage renal disease," Seminars in Dialysis, vol. 19, no. 4, pp. 291-296, 2006.

[8] T. Porazko, J. Kuźniar, M. Kusztal et al., "IL-18 is involved in vascular injury in end-stage renal disease patients," Nephrology Dialysis Transplantation, vol. 24, no. 2, pp. 589-596, 2009.

[9] T. Stompór, M. Pasowicz, W. Sułowicz et al., "An association between coronary artery calcification score, lipid profile, and selected markers of chronic inflammation in ESRD patients treated with peritoneal dialysis," American Journal of Kidney Diseases, vol. 41, no. 1, pp. 203-211, 2003.

[10] T. K. Hendrikx, E. A. F. J. van Gurp, W. M. Mol et al., "End-stage renal failure and regulatory activities of $\mathrm{CD}^{+} \mathrm{CD} 25^{\text {bright+ }} \mathrm{FoxP}^{+}$T-cells," Nephrology Dialysis Transplantation, vol. 24, no. 6, pp. 1969-1978, 2009.

[11] K. W. Kim, B. H. Chung, E. J. Jeon et al., "B cell-associated immune profiles in patients with end-stage renal disease (ESRD)," Experimental \& Molecular Medicine, vol. 44, no. 8, pp. 465-472, 2012.

[12] C. Libetta, T. Rampino, and A. Dal Canton, "Polarization of t-helper lymphocytes toward the Th2 phenotype in uremic patients," American Journal of Kidney Diseases, vol. 38, no. 2, pp. 286-295, 2001.

[13] C. Libetta, P. Esposito, V. Sepe et al., "Effects of different peritoneal dialysis fluids on the Th1/Th2 balance," European Cytokine Network, vol. 22, no. 1, pp. 24-31, 2011.

[14] A. Borazan, H. Ustün, Y. Ustundag et al., "The effects of peritoneal dialysis and hemodialysis on serum tumor necrosis factor-alpha, interleukin-6, interleukin-10 and C-reactiveprotein levels," Mediators of Inflammation, vol. 13, no. 3, pp. 201204, 2004.

[15] N. D. Vaziri, M. V. Pahl, A. Crum, and K. Norris, "Effect of uremia on structure and function of immune system," Journal of Renal Nutrition, vol. 22, no. 1, pp. 149-156, 2012.

[16] S. Kato, M. Chmielewski, H. Honda et al., "Aspects of immune dysfunction in end-stage renal disease," Clinical Journal of the American Society of Nephrology, vol. 3, no. 5, pp. 1526-1533, 2008.

[17] C. Libetta, V. Sepe, and A. Dal Canton, "Bio-incompatibility and Th2 polarization during regular dialysis treatment," International Reviews of Immunology, vol. 29, no. 6, pp. 608-625, 2010.

[18] B. H. Chung, K. W. Kim, I. O. Sun et al., "Increased interleukin17 producing effector memory $\mathrm{T}$ cells in the end-stage renal disease patients," Immunology Letters, vol. 141, no. 2, pp. 181-189, 2012.

[19] J. Zhang, G. Hua, X. Zhang, R. Tong, X. Du, and Z. Li, "Regulatory $\mathrm{T}$ cells/T-helper cell 17 functional imbalance in uraemic patients on maintenance haemodialysis: a pivotal link between microinflammation and adverse cardiovascular events," Nephrology, vol. 15, no. 1, pp. 33-41, 2010.

[20] M. Pruijm, B. Ponte, P. Vollenweider et al., "Not all inflammatory markers are linked to kidney function: results from a population-based study," The American Journal of Nephrology, vol. 35, no. 3, pp. 288-294, 2012.

[21] P. Stenvinkel, M. Ketteler, R. J. Johnson et al., "IL-10, IL-6, and TNF- $\alpha$ : central factors in the altered cytokine network of uremia - the good, the bad, and the ugly," Kidney International, vol. 67, no. 4, pp. 1216-1233, 2005.

[22] N. R. Powe, B. Jaar, S. L. Furth, J. Hermann, and W. Briggs, "Septicemia in dialysis patients: incidence, risk factors, and prognosis," Kidney International, vol. 55, no. 3, pp. 1081-1090, 1999.

[23] A. Saini, A.-S. Nasser, and C. E. H. Stewart, "Waste management-cytokines, growth factors and cachexia," Cytokine and Growth Factor Reviews, vol. 17, no. 6, pp. 475-486, 2006.

[24] J. Gupta, N. Mitra, P. A. Kanetsky et al., "Association between albuminuria, kidney function, and inflammatory biomarker profile in CKD in CRIC," Clinical Journal of the American Society of Nephrology, vol. 7, no. 12, pp. 1938-1946, 2012.

[25] K. Kalantar-Zadeh, J. D. Kopple, G. Block, and M. H. Humphreys, "A malnutrition-inflammation score is correlated with morbidity and mortality in maintenance hemodialysis patients," The American Journal of Kidney Diseases, vol. 38, no. 6, pp. 1251-1263, 2001.

[26] I. Beberashvili, A. Azar, I. Sinuani et al., "Objective Score of Nutrition on Dialysis (OSND) as an alternative for the malnutrition-inflammation score in assessment of nutritional risk of haemodialysis patients," Nephrology Dialysis Transplantation, vol. 25, no. 8, pp. 2662-2671, 2010.

[27] M. Girndt, C. Ulrich, H. Kaul, U. Sester, M. Sester, and H. Köhler, "Uremia-associated immune defect: the IL-10-CRP axis," Kidney International Supplement, vol. 63, no. 84, pp. S76S79, 2003.

[28] V. Stankovic-Popovic, V. Nesic, D. Popovic et al., "Effects of conventional versus biocompatible peritoneal dialysis solutions on peritoneal and systemic inflammation, malnutrition and atherosclerosis in CAPD patients," Clinical Nephrology, vol. 76, no. 4, pp. 314-322, 2011.

[29] Y.-H. Hwang, M.-J. Son, J. Yang et al., "Effects of interleukin6 T15A single nucleotide polymorphism on baseline peritoneal solute transport rate in incident peritoneal dialysis patients," Peritoneal Dialysis International, vol. 29, no. 1, pp. 81-88, 2009.

[30] E. Dounousi, E. Koliousi, A. Papagianni et al., "Mononuclear leukocyte apoptosis and inflammatory markers in patients with chronic kidney disease," The American Journal of Nephrology, vol. 36, no. 6, pp. 531-536, 2012.

[31] E. Majewska, Z. Baj, Z. Sulowska, J. Rysz, and M. Luciak, "Effects of uraemia and haemodialysis on neutrophil apoptosis and expression of apoptosis-related proteins," Nephrology Dialysis Transplantation, vol. 18, no. 12, pp. 2582-2588, 2003.

[32] S. Rau, A. Habicht, T. Kauke et al., "Neutrophil gelatinaseassociated lipocalin and end-stage renal disease: it is not all about the kidneys!," European Journal of Clinical Investigation, vol. 43, no. 8, pp. 816-820, 2013.

[33] G. M. Virzì, A. Clementi, M. de Cal, D. N. Cruz, and C. Ronco, "Genomics and biological activity of neutrophil gelatinaseassociated lipocalin in several clinical settings," Blood Purification, vol. 35, no. 1-3, pp. 139-143, 2013.

[34] N. E. Magnusson, M. Hornum, K. A. Jorgensen et al., "Plasma neutrophil gelatinase associated lipocalin (NGAL) is associated with kidney function in uraemic patients before and after kidney transplantation," BMC Nephrology, vol. 13, article 8, 2012.

[35] Y. Wang, K. S. L. Lam, E. W. Kraegen et al., "Lipocalin-2 is an inflammatory marker closely associated with obesity, insulin resistance, and hyperglycemia in humans," Clinical Chemistry, vol. 53, no. 1, pp. 34-41, 2007. 


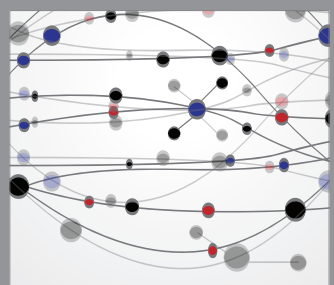

The Scientific World Journal
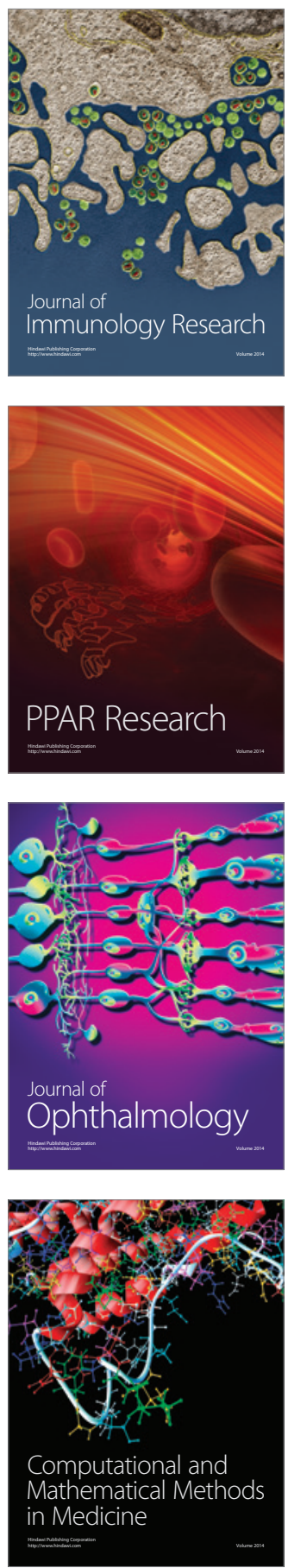

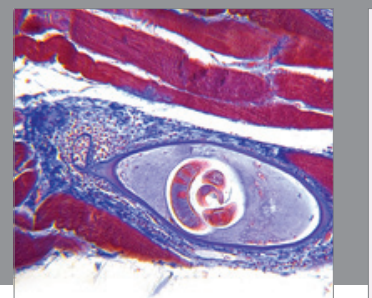

Gastroenterology

Research and Practice
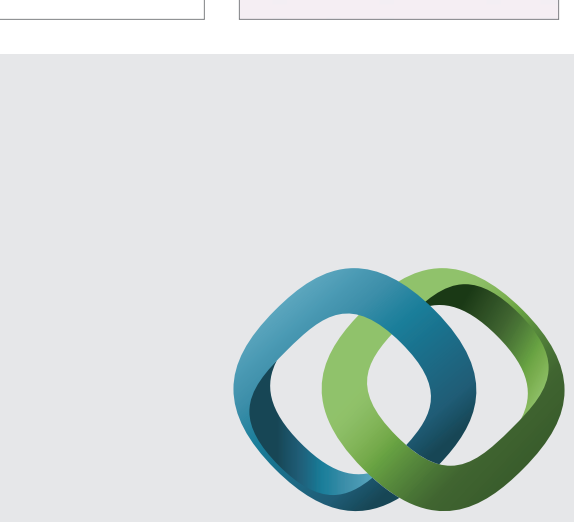

\section{Hindawi}

Submit your manuscripts at

http://www.hindawi.com
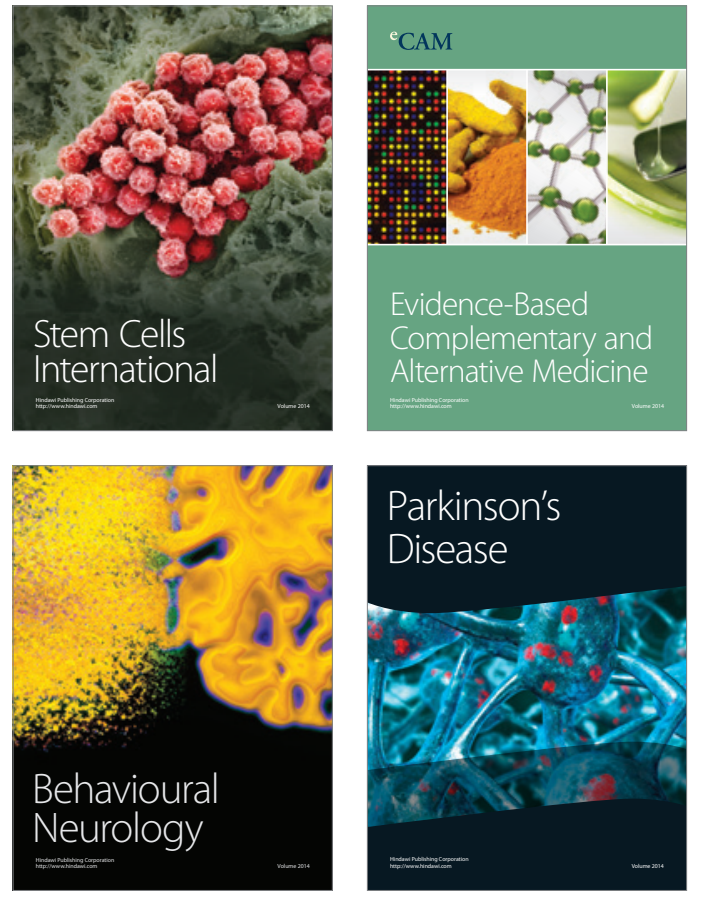
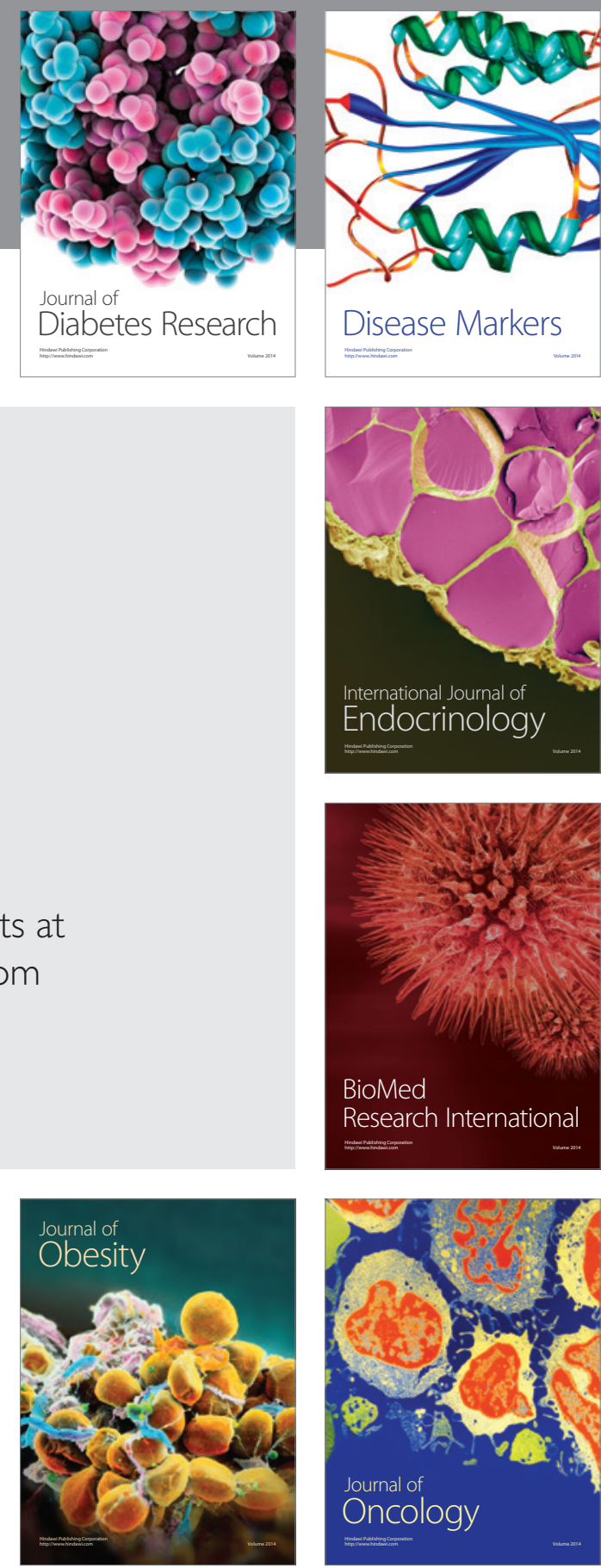

Disease Markers
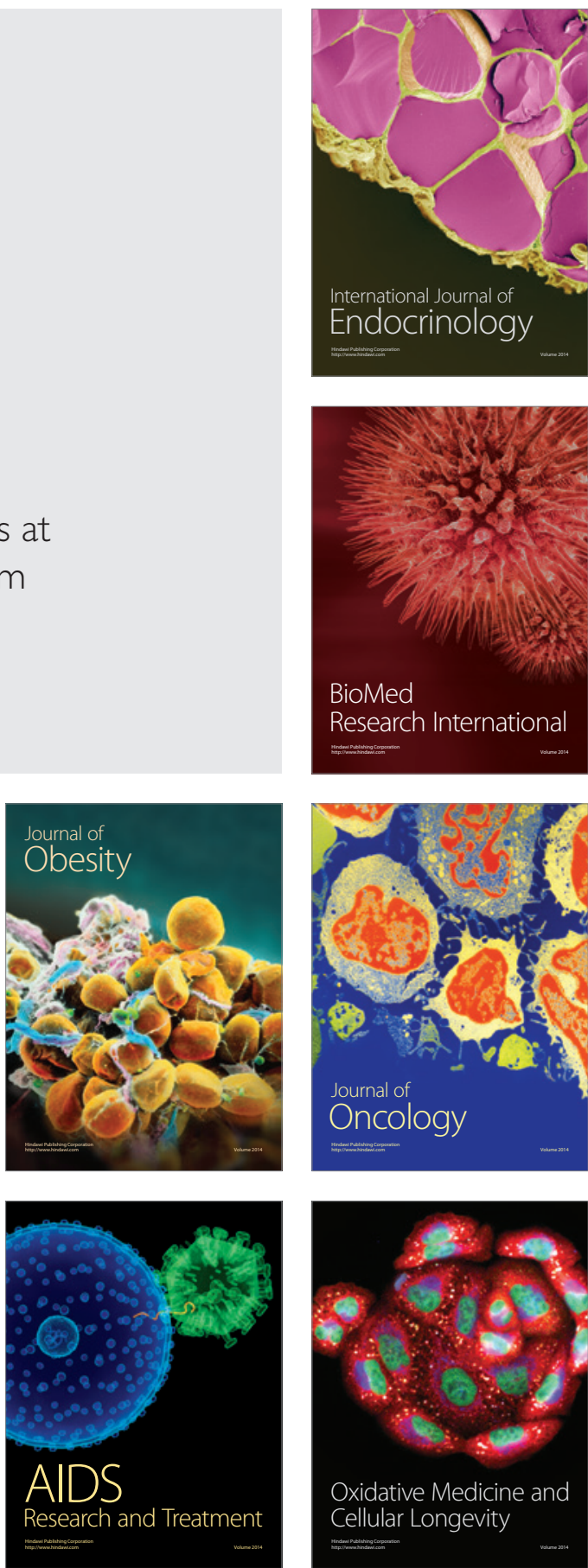